\title{
COMPOSIÇÃO DE ESPÉCIES E ÍNDICES ARBÓREOS NOS PÁTIOS DE TRÊS ESCOLAS DE GURUPI-TOCANTINS
}

\author{
Enery Martins Cezar Batista ${ }^{1}$, André Ferreira dos Santos ${ }^{2}$, Lucicléia Mendes \\ de Oliveira ${ }^{3}$, Patrícia Aparecida de Souza ${ }^{4}$ e Marcela Cristina Augistini \\ Carneiro da Silveira ${ }^{5}$
}

\begin{abstract}
Resumo: O crescimento da população humana, bem como das áreas urbanizadas, têm despertado a atenção do poder público sobre a arborização das cidades. No entanto, em relação aos ambientes escolares tem se observado que há carência de informações sobre a arborização. Assim, o objetivo deste estudo foi fazer o levantamento florístico das espécies arbóreas encontradas em três escolas de Gurupi -TO e calcular os índices arbóreos como: Índice de Densidade Arbórea (IDA), Índice de Sombreamento Arbóreo (ISA) e Índice de Área Verde Escolar (IAVE), nas três escolas. Para isso, foram coletadas informações referentes à identificação e ao diâmetro da projeção da copa de cada indivíduo arbóreo presente nas escolas. No levantamento florístico encontraram-se 50 indivíduos arbóreos distribuídos em 13 famílias e 19 espécies sendo que a espécie dominante foi Licania tomentosa (Benth) Fritsch representada por 30\%. Os maiores indices arbóreos foram observados na escola municipal Vila Nova, IDA de 0,737m²; ISA de 21,161 e IAVE de $1,555 \mathrm{~m}^{2} / a l u n o$. Pode-se concluir que nas escolas ainda há carência de árvores para melhorar o aspecto paisagístico e fornecer sombra sendo ainda necessária uma maior prioridade para as espécies nativas da flora brasileira.
\end{abstract}

Palavras-chave: Árvores. Percepção Ambiental. Sombreamento.

\section{Introdução}

De acordo com Bonametti (2008), com o crescimento da população humana e consequentemente da área urbanizada, atualmente há maior interesse do poder público sobre a arborização das cidades, especialmente com relação à qualidade e à preservação de espaços de mobilização, o qual é fortalecido e incentivado pela própria comunidade.

Entretanto, percebe-se, por meio de estudos que o meio ambiente é impactado de maneira negativa pelo crescimento vertical e horizontal das cidades, o qual acontece de maneira acelerada e desordenada, uma vez que a substituição do ecossistema natural por edificações, pavimentações, aterros, dentre outros, propicia problemas hídricos, sonoros e visuais para os habitantes. Assim, planejar a arborização é imprescindível ao desenvolvimento urbano, além de evitar prejuízos para o meio ambiente (DANTAS; SOUZA, 2004).

A arborização urbana segundo Grey e Daneke (1978) pode ser definida como um conjunto de árvores que se desenvolvem em áreas públicas e privadas de uma cidade, visando ao bem-estar socioambiental, econômico e cultural de uma comunidade.

No que tange à arborização urbana, esta pode ser implantada em parques escolares e praças, como também em ruas e calçadas. Uma diferença entre esses espaços, é que em parques e praças há uma maior flexibilidade para se adotar certas espécies. Já em ruas e calçadas, o cuidado deve ser bem maior quanto, por exemplo, ao porte da árvore, uma vez que, com o passar dos anos, isso prejudicará a infraestrutura local. Contudo, quando a calçada for suficientemente larga, pode ser inserido um canteiro central ou uma faixa com grama, o que permitirá utilizar árvores de raízes superficiais (AURÉLIO JUNIOR, 2008).

\footnotetext{
'E-mail: enerymartins@yahoo.com.br

²E-mail: andrefs@mail.uft.edu.br

Universidade Federal do Tocantins - R Badejos s/n Zona Rural . Gurupi - TO - CP 66 - 77402-970

${ }^{3}$ E-mail: lucilcleiabiologa@gmail.com

${ }^{4}$ E-mail: patriciaapsouza@mail.uft.edu.br

${ }^{5}$ E-mail: marcelasilveira@uft.edu.br
} 


\section{REA - Revista de estudos ambientais (Online) v.18, n. 2, p.6-15, jul./dez. 2016}

Há uma série de benefícios relacionados à arborização, tais como: a regularização do clima; a redução da poluição atmosférica; o ajustamento do regime das chuvas; a diminuição da velocidade dos ventos; a melhoria de condições do solo urbano; o aumento de quantidade e diversidade da fauna nas cidades (principalmente de pássaros); a redução dos ruídos e, consequentemente, da poluição sonora; e além de favorecer o lazer e a recreação nas praças, jardins e parques, valoriza os imóveis $e$, fornece as cidades mais qualidade de vida (LANGOWSKI; KLECHOWICZ, 2001).

Nos ambientes escolares, a arborização desempenha um papel que vai além da melhoria ambiental, podendo servir como modelo e fonte contínua de aprendizado, pois a implementação de árvores nos pátios escolares constitui uma alternativa viável, no sentido de tornar o ambiente mais atrativo e aprazível para a comunidade escolar, associada à influência positiva dessas plantas sobre a formação ético-ambiental dos alunos (FEDRIZZI: TOMASINI; CARDOSO, 2003a).

Entretanto, ainda são escassos os estudos sobre a arborização em ambientes escolares. Segundo Fagundes et al. (2015) trabalhos nesse sentido, bem como a jardinagem, podem ser realizados em equipe visando a organização do espaço escolar, o qual proporcionará um espaço mais aconchegante e recreativo aliado a preservação do ambiente, e ainda possibilita a preparação de cidadãos mais humanizados e sensibilizados com o meio ambiente.

Para avaliar a arborização, alguns Índices Arbóreos podem ser utilizados, como: Índice de Sombreamento Arbóreo (ISA), o qual se refere ao percentual da área sombreada obtida pela soma das áreas de copas em relação à área total do ambiente estudado; o Índice de Densidade Arbórea (IDA), o qual verifica a intensidade da ocupação das árvores em determinada área (LIMA NETO; SOUZA 2009) e o Índice de Áreas Verdes (IAVE) que corresponde à relação entre a área sombreada pelo número de alunos matriculados (CALLEJAS et al., 2014).

$\begin{array}{cccc}\text { A } & \text { Sociedade } & \text { Brasileira de } \\ \text { Arborização } & \text { Urbana } & \text { (SBAU) }\end{array}$ estabeleceu que o mínimo de áreas verdes públicas deve ser de $15 \mathrm{~m}^{2}$ por habitante. No entanto, para ambientes escolares, ainda não há valores mínimos recomendados para áreas verdes, o que confirma a carência de informações relacionadas à arborização dos pátios escolares.

Diante do exposto, reforça-se a relevância deste estudo pertinente à arborização nos pátios das escolas de Gurupi, pois, dentre outras possíveis contribuições, viabiliza o contato dos alunos com as árvores, a partir das quais vários assuntos relacionados às ciências biológicas ganham margem para serem explorados. Igualmente, pode-se observar e questionar sobre a disponibilidade e compatibilização do espaço físico para o plantio de árvores apropriadas para essas condições. Sendo assim, o objetivo deste estudo foi fazer o levantamento das espécies encontradas nos pátios de três escolas do município de Gurupi - TO e posteriormente, calcular os respectivos índices arbóreos como forma de auxiliar nas estratégias de melhoria desses ambientes de aprendizagem.

\section{Material e métodos}

\section{1 Área de estudo}

O Município de Gurupi está localizado na região sul do Estado do Tocantins, a $245 \mathrm{~km}$ da capital do estado, Palmas, e $742 \mathrm{~km}$ da capital do Estado Soberano, Brasília-DF. A cidade de Gurupi está situada no limite divisório de águas dos rios Araguaia e Tocantins, às margens da BR-153, mais precisamente no quilômetro 663 no sentido Brasília-DF a Belém-PA, entre os paralelos 11 e 12, latitude 11\%43'44" sul, e longitude $49^{\circ} 04^{\prime} 08^{\prime \prime}$ norte. Faz limite ao norte com a cidade de Aliança, ao sul com as cidades de Cariri e Sucupira, a oeste com o município de Dueré e, a leste com a cidade de Peixe, e possui uma população de 75.000 habitantes (IBGE, 2010).

Para a realização do estudo foram selecionadas três escolas de ensino fundamental, todas localizadas no perímetro urbano de Gurupi - TO (Figura 1). A Tabela 1 informa os nomes das escolas, número de alunos e as respectivas áreas de cada uma, cujos valores foram utilizados para os cálculos dos índices arbóreos. Nas escolas foram feitas visitas para o reconhecimento da área escolar e posteriormente foi realizado $o$ levantamento florístico por meio de nomes comuns e as medições de projeções das copas das árvores. 


\section{REA - Revista de estudos ambientais (Online) v.18, n. 2, p.6-15, jul./dez. 2016}

Figura 1 - Vista das escolas estaduais Hercília Carvalho da Silva (A), Aeroporto III (B) e a municipal

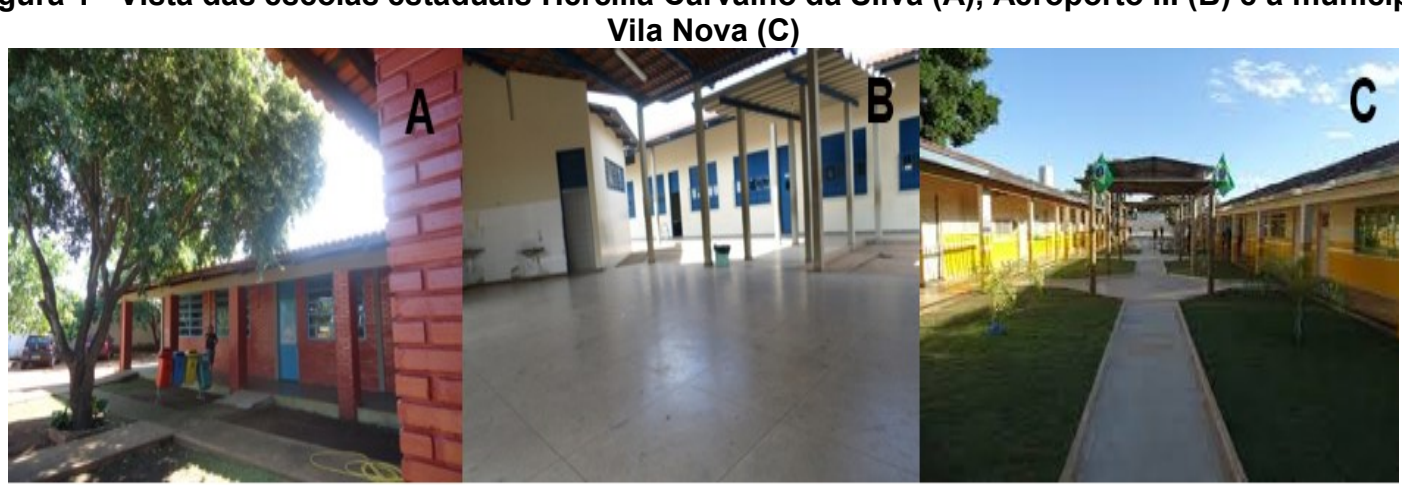

Fonte: Autores (2016)

A identificação das espécies inicialmente foi feita por meio do nome popular e depois pelo nome científico e família botânica. Em caso de dúvidas, foram feitos registros fotográficos e coletas de amostras botânicas para serem comparadas com bibliografias especializadas, além da consulta ao herbário da Universidade Federal do Tocantins. Para a obtenção das projeções das copas das árvores foi utilizada uma trena de 20 metros, sendo coletados os valores de dois raios (R1 e R2) e o diâmetro longitudinal.

Tabela 1 - Identificação das escolas estudadas em Gurupi - Tocantins

\begin{tabular}{lllll}
\hline NI & Nome das escolas & Ano & No de alunos $^{\circ}$ & Área $\left(\mathbf{m}^{\mathbf{2}}\right)$ \\
\hline $\mathbf{0 1}$ & Hercília Carvalho da Silva & $1^{\circ}$ ao $9^{\circ}$ & 272 & $8.677,50$ \\
$\mathbf{0 2}$ & Aeroporto III & $1^{\circ}$ ao $9^{\circ}$ & 167 & $1.221,00$ \\
$\mathbf{0 3}$ & Municipal Vila Nova & $1^{\circ}$ ao $5^{\circ}$ & 314 & $2.308,12$ \\
\hline
\end{tabular}

Onde NI: Número de identificação das escolas

Fonte: Autores (2016)

\subsection{Cálculo da área verde}

Para o cálculo da área verde das árvores dos pátios escolares e área ocupada pela copa foi adotada a metodologia baseada em Sampaio e Angelis (2008), sendo a área verde individual calculada a partir do raio médio $(r)$ de cada unidade de observação (árvore), cujo cálculo foi realizado com uso da equação 1.

$$
r=1 / 4(\text { Long }+R 1+R 2)
$$

Onde: $r=$ raio médio; Long = diâmetro longitudinal; $\mathrm{R} 1=$ raio em direção à área aberta do pátio e $\mathrm{R} 2$ = raio em direção à construção.

Após a obtenção do raio médio, a área sombreada por cada árvore foi obtida pela equação $\mathrm{AV}=\Pi \cdot \mathrm{r}^{2}(2)$, e a área verde (AV) total de cada escola foi obtida pelo somatório da área de cada projeção de copa de todas as árvores avaliadas.
Após a identificação das espécies, as árvores foram classificadas quanto à origem em exóticas e nativas. Foram consideradas nativas aquelas pertencentes à flora brasileira, cuja categorização se deu por meio de bibliografias especializadas (LORENZI, 2002a; LORENZI, 2002b; LORENZI, 2008; LORENZI et al., 2003; CARVALHO, 2008) e quanto às famílias botânicas, seguiu-se a classificação da APG IV (APG, 2016). Após a contabilização e medições dos indivíduos, foram calculados os Índices Arbóreos.

\subsection{Cálculo dos Índices Arbóreos}

Para o cálculo dos Índices Arbóreos e, tomando como base estudos realizados sobre arborização de ambientes escolares, foram consideradas apenas as árvores, desconsiderando-se os indivíduos arbustivos, tendo em vista que estes apresentam menor potencial de 


\section{REA - Revista de estudos ambientais (Online) v.18, n. 2, p.6-15, jul./dez. 2016}

sombreamento. Dessa forma, na escola estadual Hercília Carvalho da Silva foram encontrados 25 indivíduos dos quais foram considerados apenas 15. $\mathrm{Na}$ escola municipal Vila Nova havia 24 indivíduos dos quais se considerou 17. Enquanto na escola Aeroporto III, não foi possível realizar esse cálculo pela ausência da vegetação arbórea.

Os índices arbóreos (Índice de Densidade Arbóreo, Índice de Sombreamento Arbóreo e Índice de Área Verde escolar) foram calculados baseados na metodologia proposta por Simões et al. (2001), Lima Neto e Souza (2009) e Callejas et al. (2014).

Simões et al. (2001) propõem informações a respeito do Índice de Densidade Arbóreo (IDA) e do Índice de Sombreamento Arbóreo (ISA). O primeiro consiste no número de árvores existentes em cada $100 \mathrm{~m}^{2}$. O cálculo revela se a área em estudo apresenta uma deficiência ou abundância de vegetação arbórea, o qual é determinado pela equação 2 .

$$
\mathrm{IDA}=\frac{\mathrm{N}}{\mathrm{AT}\left(\mathrm{m}^{2}\right)} \times 100
$$

Onde: IDA= Índice de Densidade Arbóreo; $\mathrm{N}=$ Número de árvores em cada escola; e AT = Área Total em $\mathrm{m}^{2}$ de cada escola.

O Índice de Sombreamento Arbóreo, segundo Lima Neto e Souza (2009), referese à percentagem de área sombreada em relação à área total. Por meio deste, obtémse o potencial de sombra resultante da soma das áreas de projeção das copas, calculado pela equação 3 .

$$
\mathrm{ISA}=\frac{\mathrm{AS}\left(\mathrm{m}^{2}\right)}{\mathrm{AT}\left(\mathrm{m}^{2}\right)} \times 100
$$

Onde ISA = Índice de Sombreamento Arbóreo; AS (Área sombreada) = Área ocupada pela projeção das copas das árvores; e AT (Área total) $=$ Área em $\mathrm{m}^{2} \mathrm{de}$ cada escola.

O Índice de Área Verde Escolar (IAVE) foi calculado conforme a metodologia utilizada por Callejas et al. (2014), que é obtido por meio da relação entre a área sombreada total de árvores encontradas na escola pelo número de alunos matriculados no ano letivo em avaliação. Assim, o IAVE foi calculado pela equação 4 .

$$
\mathrm{IAVE}=\frac{\mathrm{AS}\left(\mathrm{m}^{2}\right)}{\text { Alunos matriculados }}
$$

Onde IAVE = Índice de Área Verde escolar e AS (Área sombreada) = Área ocupada pela projeção das copas das árvores.

\section{Resultados e discussão}

No levantamento florístico das três escolas de Gurupi, encontraram-se 50 indivíduos arbóreos pertencentes a 19 espécies de 13 famílias botânicas. As espécies que mais se destacaram foram a Licania tomentosa representando $30 \%$ das árvores encontradas seguida por Dypsis lutescens com $12 \%$, enquanto Anacardium occidentale e Malpighia emarginata apresentaram $10 \%$ cada uma (Tabela 2). A dominância da Licania tomentosa em duas das três escolas de Gurupi -TO - deve-se ao fato de ser uma espécie que apresenta rápido crescimento e também por falta de conhecimento por parte da população sobre a diversidade de espécies utilizadas na arborização (SANTOS; JOSÉ; SOUSA, 2013). Outro fator que contribui para o uso da referida espécie deve-se aos seguintes aspectos, boa capacidade de germinação, copa frondosa, perenifólia, altura de 8 a 15 metros quando adulta e não apresentar raízes agressivas (Lorenzi, 2002a).

Das 13 famílias botânicas encontradas neste estudo, as que apresentaram maior representatividade quanto ao número de espécies foram: Fabaceae (três espécies), Arecaceae, Bignoniaceae, Moraceae e Rubiaceae (duas espécies). As demais famílias apresentaram uma única espécie cada. Apesar de a família Chrysobalanaceae apresentar apenas uma única espécie, esta foi a que teve mais indivíduos plantados, 15 (Tabela 2).

Quando comparado os resultados deste levantamento florístico com a arborização das praças de Gurupi -TO -, pode-se constatar, por meio dos estudos de Santos, José e Sousa (2013), que as famílias Fabaceae, Arecaceae e Bignoniaceae também foram as mais representativas quanto ao número de espécies, nesta ordem respectivamente. Ademais, apresentaram semelhança quanto à maior representatividade de indivíduos da família Chrysobalanaceae, representada por Licania tomentosa. Isso indica que a vegetação utilizada para arborizar as escolas é um reflexo daquela empregada em praças e vias públicas da cidade. 
REA - Revista de estudos ambientais (Online) v.18, n. 2, p.6-15, jul./dez. 2016

Tabela 2 - Lista das espécies encontradas nas três escolas, em Gurupi - TO -, e a classificação segundo a família, nome científico, nome popular, número de indivíduos $(\mathrm{NI})$, origem $(0)$ e frequência ( $F \%)$

\begin{tabular}{|c|c|c|c|c|c|}
\hline FAMÍLIA & NOME CIENTÍFCO & NOME POPULAR & NI & $\mathbf{0}$ & $F(\%)$ \\
\hline Anacardiaceae & Anacardium occidentale L. & Caju & 5 & $\mathrm{~N}$ & 10,0 \\
\hline Annonaceae & Annona squamosa L. & Ata & 1 & $\mathrm{~N}$ & 2,0 \\
\hline \multirow[t]{2}{*}{ Arecaceae } & Caryota urens L. & Rabo-de-peixe & 2 & $\mathrm{E}$ & 4,0 \\
\hline & Dypsis lutescens (H. Wendl.) Beentje \& J. Dransf. & Areca-bambu & 6 & $\mathrm{E}$ & 12,0 \\
\hline \multirow[t]{2}{*}{ Bignoniaceae } & Handroanthus impetiginosus (Mart. ex DC.) Mattos & Ipê-roxo & 2 & $\mathrm{~N}$ & 4,0 \\
\hline & Handroanthus heptaphyllus (Vell.) Mattos & Ipê-rosa & 2 & $\mathrm{~N}$ & 4,0 \\
\hline Caricaceae & Carica papaya L. & Mamão & 1 & $E$ & 2,0 \\
\hline Chrysobalanaceae & Licania tomentosa (Benth.) Fritsch & Oiti & 15 & $\mathrm{~N}$ & 30,0 \\
\hline Cycadaceae & Cycas revoluta Thunb. & Palmeira sagu-cica & 1 & $E$ & 2,0 \\
\hline \multirow[t]{3}{*}{ Fabaceae } & $\begin{array}{l}\text { Poincianella pluviosa var. peltophoroides } \\
\text { (Benth) L.P.Queiroz }\end{array}$ & Sibipiruna & 1 & $\mathrm{~N}$ & 2,0 \\
\hline & Delonix regia (Bojer ex Hook.) Raf. & Flamboyant & 1 & $E$ & 2,0 \\
\hline & Hymenaea stigonocarpa Mart.ex Hayne & Jatobá-do-cerrado & 1 & $\mathrm{~N}$ & 2,0 \\
\hline Malpighiaceae & Malpighia emarginata DC. & Acerola & 5 & $E$ & 10,0 \\
\hline \multirow[t]{2}{*}{ Moraceae } & Brosimum gaudichaudii Trécul & Inharé & 1 & $\mathrm{~N}$ & 2,0 \\
\hline & Ficus benjamina L. & Ficus & 1 & $E$ & 2,0 \\
\hline Myrtaceae & Syzygium malaccense (L.) Merr. \& L.M. Perry. & Jambo-roxo & 2 & $E$ & 4,0 \\
\hline Punicaceae & Punica granatum L. & Romã & 1 & $E$ & 2,0 \\
\hline \multirow[t]{2}{*}{ Rubiaceae } & Ixora coccinea L. & Ixora ornamental & 1 & $\mathrm{E}$ & 2,0 \\
\hline & Citrus $\mathrm{x}$ aurantium $\mathrm{L}$. & Limoeiro & 1 & $\mathrm{E}$ & 2,0 \\
\hline Total $=13$ & 19 & & 50 & & \\
\hline
\end{tabular}

Apesar de haver várias espécies nas escolas avaliadas, é necessária maior diversidade, pois segundo relatado por Silva, Paiva e Gonçalves (2004) não é aconselhável que uma espécie ultrapasse a porcentagem de 12 a $15 \%$ do total de indivíduos, tendo em vista que a população homogênea pode estar susceptível a doenças e pragas específicas que podem dizimar a arborização, como consequência de paisagem monótona.

O uso de espécies nativas também é importante, porque estas são adaptadas às condições de clima e solo regionais, auxiliam na construção de uma área semelhante à natural, sendo também uma forma de divulgação e valorização da flora local, que contribui para a manutenção da biodiversidade (ALVAREZ et al., 2012).

Quando avaliada a distribuição de espécies para cada escola, pode-se observar que na escola Aeroporto III, foi encontrada somente uma planta, a Sagu-de-jardim (Cycas revoluta). Isso ocorreu porque a escola não apresenta área útil, fator que limita o plantio das espécies arbóreas. Já nas demais escolas foram encontradas diversas espécies de plantas. Apesar de a escola Aeroporto III não possuir área útil nas dependências internas é possível fazer uso da jardinagem com a reutilização de alguns materiais descartáveis e ainda arborizar a área externa da escola. Essa iniciativa poderá auxiliar na melhoria do aspecto estético da escola, viabilizar o contato dos alunos com as plantas e ainda esse ambiente pode ser explorado para conscientizar os alunos sobre a importância das plantas e a preservação das mesmas.

Segundo Fagundes et al. (2015), a gestão do ambiente começando pela escola pode viabilizar a transformação social e gerar novas posturas frente ao ambiente os quais juntamente com a educação ambiental promovem a sensibilização e reconhecimento da importância do ambiente equilibrado. Assim, o envolvimento dos alunos em projetos interdisciplinares é fundamental para proporcionar o conhecimento, a aprendizagem, a 


\section{REA - Revista de estudos ambientais (Online) v.18, n. 2, p.6-15, jul./dez. 2016}

criatividade e desenvolver a cultura ambiental.

$\mathrm{Na}$ escola Estadual Hercília Carvalho da Silva foram encontrados 25 indivíduos, distribuídos em 11 espécies, sendo 6 $(54,54 \%)$ nativas e $5(45,45 \%)$ exóticas. Das espécies encontradas as duas mais frequentes foram Licania tomentosa (Oiti) e Malpighia emarginata (Acerola) as quais representaram 28,0 e 20,0\% dos indivíduos, respectivamente (Tabela 3 ).

Tabela 3 - Lista das plantas da escola estadual Hercília Carvalho da Silva, e a classificação segundo a família, nome científico, nome popular, número de indivíduos (NI), origem (O) e frequência ( $\mathrm{F} \%)$

\begin{tabular}{|c|c|c|c|c|c|}
\hline Família & Nome científico & Nome popular & NI & 0 & $F(\%)$ \\
\hline \multirow[t]{2}{*}{ Arecaceae } & Dypsis lutescens (H. Wendl.) Beentje \& J. Dransf. & Areca-bambu* & 2 & $E$ & 8,0 \\
\hline & Caryota urens L. & Rabo-de-peixe* & 2 & $E$ & 8,0 \\
\hline \multirow[t]{2}{*}{ Bignoniaceae } & Handroanthus heptaphyllus (Vell.) Mattos & Ipê-rosa & 2 & $\mathrm{~N}$ & 8,0 \\
\hline & Handroanthus impetiginosus (Mart. ex DC.) Mattos & Ipê-roxo & 1 & $\mathrm{~N}$ & 4,0 \\
\hline Chrysobalanaceae & Licania tomentosa (Benth.) Fritsch & Oiti & 7 & $\mathrm{~N}$ & 28,0 \\
\hline \multirow[t]{2}{*}{ Fabaceae } & $\begin{array}{l}\text { Hymenaea stigonocarpa } \\
\text { Mart.ex Hayne }\end{array}$ & Jatobá-do-cerrado & 1 & $\mathrm{~N}$ & 4,0 \\
\hline & $\begin{array}{l}\text { Poincianella pluviosa var. peltophoroides (Benth) } \\
\text { L.P.Queiroz }\end{array}$ & Sibipiruna & 1 & $\mathrm{~N}$ & 4,0 \\
\hline Malpighiaceae & Malpighia emarginata DC. & Acerola* & 5 & $E$ & 20,0 \\
\hline Myrtaceae & Syzygium malaccense (L.) Merr. \& L.M. Perry. & Jambo-roxo & 2 & $E$ & 8,0 \\
\hline \multirow[t]{2}{*}{ Rubiaceae } & Ixora coccinea L. & |xora ornamental ${ }^{*}$ & 1 & $E$ & 4,0 \\
\hline & Citrus $\mathrm{x}$ aurantium $\mathrm{L}$. & Limoeiro & 1 & $E$ & 4,0 \\
\hline Total $=7$ & 11 & & 25 & & 100 \\
\hline
\end{tabular}

Ao analisar a frequência de distribuição das espécies presentes na escola estadual Hercília Carvalho da Silva (Tabela 3), nota-se que a quantidade de indivíduos da espécie Licania tomentosa e Malpighia emarginata ultrapassam a frequência de distribuição de 12 a $15 \%$ sugerida por Silva, Paiva e Gonçalves (2004).

$\mathrm{Na}$ escola municipal Vila Nova foram encontrados 24 indivíduos distribuídos em 10 espécies, sendo 5 nativas. As três espécies mais frequentes foram a Licania tomentosa (Oiti), Anacardium occidentale (Caju) e Dypsis lutescens (Areca bambu) as quais representaram 33,3, 20,8 e 16,7\%, respectivamente (Tabela 4 ).

Nota-se que semelhante à escola estadual Hercília Carvalho da Silva mencionada anteriormente, a escola municipal Vila Nova, também contém espécies que ultrapassaram a frequência de distribuição de 12 a $15 \%$, que é o recomendado para a arborização. Segundo Callejas et al. (2014) que estudaram a arborização de três escolas em Cuiabá-MT, igualmente verificou-se que várias espécies apresentaram frequência de distribuição superior ao valor recomentado pela literatura. Nas escolas avaliadas pelos autores ocorreu uma alta distribuição de Licania tomentosa, semelhante ao presente estudo. Outro fator que chamou atenção foi a presença de várias espécies frutíferas, pois além de servirem como fonte de alimento para os alunos, também podem auxiliar no ensino de ciências naturais.

Sobre isso, Véras et al. (2014) descrevem que na escola estadual do Ensino Fundamental João Suassuna no município de Catolé do Rocha - PB -, a arborização foi implantada exatamente com uso de frutíferas com a finalidade de combater a extinção de determinadas espécies e proporcionar a conscientização dos alunos quanto ao ambiente, além de servir como fonte de alimento para os mesmos. Esse projeto foi tão importante que despertou a atenção dos alunos quanto à preservação do meio ambiente ao ponto de se interessarem por outros projetos como compostagem e destino do resíduo sólido. Tais iniciativas mostram o quanto é importante formar cidadãos preocupados com o ambiente, pois 


\section{REA - Revista de estudos ambientais (Online) v.18, n. 2, p.6-15, jul./dez. 2016}

contribuem para a redução dos problemas atuais e ainda podem evitar impactos futuros desde que medidas preventivas sejam tomadas.

Tabela 4 - Lista das espécies arbóreas da escola municipal Vila Nova, e a classificação segundo a família, nome científico, nome popular, número de indivíduos (NI), origem (O) e frequência (F)

\begin{tabular}{|c|c|c|c|c|c|}
\hline Família & Nome científico & Nome popular & NI & 0 & $F(\%)$ \\
\hline Anacardiaceae & Anacardium occidentale L. & Caju & 5 & $\mathrm{~N}$ & 20,8 \\
\hline Annonaceae & Annona squamosa L. & Ata & 1 & $\mathrm{~N}$ & 4,2 \\
\hline Arecaceae & Dypsis lutescens (H. Wendl.) Beentje \& J. Dransf. & Areca bambu* & 4 & $E$ & 16,7 \\
\hline Bignoniaceae & Handroanthus impetiginosus (Mart. ex DC.) Mattos & Ipê roxo & 1 & $\mathrm{~N}$ & 4,2 \\
\hline Caricaceae & Carica papaya L. & Mamão* & 1 & $E$ & 4,2 \\
\hline Chrysobalanaceae & Licania tomentosa (Benth.) Fritsch & Oiti & 8 & $\mathrm{~N}$ & 33,3 \\
\hline Fabaceae & Delonix regia (Bojer ex Hook.) Raf. & Flamboyant** & 1 & $E$ & 4,2 \\
\hline \multirow[t]{2}{*}{ Moraceae } & Ficus benjamina L. & Fícus & 1 & $\mathrm{E}$ & 4,2 \\
\hline & Brosimum gaudichaudii Trécul & Inharé & 1 & $\mathrm{~N}$ & 4,2 \\
\hline Punicaceae & Punica granatum L. & Romã* & 1 & $E$ & 4,2 \\
\hline Total & & 10 & 24 & & 100 \\
\hline
\end{tabular}

Ao comparar as três escolas do presente estudo com as analisadas por Fredizzi et al. (2003b) pode-se constatar que a realidade das mesmas são semelhantes quanto a quantidade e qualidade da vegetação, já que foi constatado a ausência de vegetação devido o pátio estar pavimentado, tal como ocorreu na escola Aeroporto III.

Ainda com relação à origem das espécies encontradas no levantamento arbóreo feito nas três escolas de Gurupi-TO-, apesar de haver menos espécies nativas (8) que exóticas (11) pode-se constatar que a maioria da população foi representada por exemplares nativos. A alta representatividade de espécies exóticas nesses ambientes se justifica pela introdução de novas espécies, sem o devido planejamento.

Segundo Ziller (2001), as espécies exóticas podem ser utilizadas desde que seja de forma cautelosa, pois estas podem se tornar uma ameaça aos ecossistemas, às populações e às outras espécies, causando impactos sociais, culturais e ambientais. As espécies exóticas uma vez implantadas podem competir com as nativas por nutrientes, luz solar e espaço físico, podendo tornar-se invasoras. Ademais, o potencial das exóticas em alterar o ambiente é tão preocupante que, atualmente, são consideradas a maior ameaça à biodiversidade.

Quanto aos índices arbóreos, podese constatar que os valores variaram entre as escolas avaliadas. Na escola estadual Aeroporto III, todos os índices foram nulos tendo em vista que não havia árvores.

Para as demais escolas, os valores do Índice de Sombreamento Arbóreo (ISA) variou de 4,870 a 21,161, o Índice de Densidade Arbórea (IDA) de 0,173 a 0,737 árvores para cada $100 \mathrm{~m}^{2}$, enquanto o Índice de Área Verde Escolar (IAVE) praticamente não houve diferença (Tabela 5). Portanto, os melhores índices foram encontrados na escola municipal Vila Nova, os quais foram: ISA de 21,161 , IDA 0,737 árvores $/ \mathrm{m}^{2}$ e IAVE $1,555 \mathrm{~m}^{2}$ /aluno.

Analisando 0 Índice de Sombreamento Arbóreo (ISA) da escola municipal Vila Nova $(21,161 \%)$, constatou-se que ele ainda é considerado baixo quando comparado com os estudos de Callejas et al. (2014), o qual obteve índice de 33,40\%. Esses valores de 21,161 para o Índice de Sombreamento Arbóreo (ISA), tanto neste estudo, quanto no de Callejas et al. (2014), sugerem a carência de árvores no espaço escolar para proporcionar melhoria na temperatura ambiente.

Tais resultados sugerem que ainda é necessário plantar mais árvores na referida escola, pois segundo afirma Fedrizzi et al. 


\title{
REA - Revista de estudos ambientais (Online) v.18, n. 2, p.6-15, jul./dez. 2016
}

(2003b) a vegetação nos pátios escolares é de suma importância para proporcionar benéficos térmicos no local, o qual será desfrutado pelos alunos e demais usuários das edificações. Além disso, tal espaço tem despertado a atenção devido a dois motivos: primeiro, o espaço para as crianças brincarem está sendo reduzido devido ao crescimento das cidades e o segundo motivo se refere ao interesse voltado para este espaço que possibilita a exploração de assuntos ecológicos e viabiliza a interação entre os alunos em área aberta.

Tabela 5 - Lista das três escolas avaliadas em Gurupi, TO, com o seus respectivos índices arbóreos

\begin{tabular}{|c|c|c|c|c|c|c|}
\hline ESCOLAS & $\mathrm{AS}\left(\mathrm{m}^{2}\right)$ & NAlunos & NÁrvores & ISA & IDA(Árvore/m²) & IAVEm²/Aluno \\
\hline Estadual Aeroporto III & 0,0 & 167 & 0 & 0,0 & 0,0 & 0,00 \\
\hline Hercília C. da Silva & 422,614 & 272 & 15 & 4,870 & 0,173 & 1,554 \\
\hline Municipal Vila Nova & 488,413 & 314 & 17 & 21,161 & 0,737 & 1,555 \\
\hline
\end{tabular}
arbórea).

Legenda: área sombreada (AS); ISA (índice de sombreamento arbóreo); IDA (índice de densidade

Fonte: Autores (2016)

Quanto ao Índice de Densidade Arbóreo, também foi verificado baixos valores entre as escolas avaliadas. No entanto, o valor da escola municipal Vila Nova $(0,737)$ foi similar ao encontrado por Callejas et al. (2014) em uma das escolas com IDA igual a 0,80 indivíduos para cada $100 \mathrm{~m}^{2}$. Isso indica que o índice é considerado bom, entretanto, está abaixo da recomendação mínima, a qual corresponde a pelo menos um indivíduo para cada $100 \mathrm{~m}^{2}$.

Com relação ao Índice de Área Verde Escolar (IAVE), igualmente foram encontrados valores insatisfatórios para todas as escolas, especialmente para a Aeroporto III devido à ausência de árvores e espaço disponível para plantio de árvores. Nas outras duas escolas, os valores apresentaram uma diferença de apenas $0,001 \mathrm{~m}^{2} /$ aluno, sendo que o maior valor foi de 1,555 para a escola municipal Vila Nova. Comparativamente aos valores $(2,72 ; 11,40$ e 2,30) encontrados por Callejas et al. (2014), nota-se a necessidade de medidas corretivas para melhorar a arborização destas escolas. O valor do IAVE de 1,555 $\mathrm{m}^{2}$ /aluno, mostra-se muito aquém do que é recomendado pela SBAU (1996), cujo índice é de $15 \mathrm{~m}^{2} /$ habitante.

\section{Conclusões}

Na escola estadual Hercília Carvalho da Silva se encontrou diversas espécies, sendo a maioria nativa, enquanto na escola municipal Vila a frequência de nativas e exóticas foi igual.

Os melhores resultados para os índices arbóreos foram encontrados na escola municipal Vila Nova.

A espécie que mais se destacou foi a Licania tomentosa (Benth) Fritsch.

Nas escolas ainda há carência de árvores para melhorar o aspecto paisagístico e fornecer sombra e, ainda, é necessário dar maior prioridade para as espécies nativas da flora brasileira.

\section{Composition of Species and Arboreal indexes in the Patios of Three Schools of Gurupi - Tocantins}

\begin{abstract}
The growth of the human population as well as urbanized areas has attract the attention of the government about the afforestation of cities. However, in relation to school environments, it has been observed that there is a lack of information about afforestation. Thus, the aim of this study was make the floristic survey of arboreal species found in three schools of Gurupi -TO and calculate the arboreal indexes as: Arboreal Density Index (ADI), Shading Vegetation Index (SVI) and School Green Area Index (SGAI), in three schools of Gurupi -TO. For this, information regarding the identification and diameter of the crown projection of each arboreal individual present in the schools was collected. In the floristic survey were found 50 arboreal
\end{abstract}




\section{REA - Revista de estudos ambientais (Online) v.18, n. 2, p.6-15, jul./dez. 2016}

specimens distributed in 13 families and 19 species, being Licania tomentosa (Benth) Fritsch the dominant species, represented by $30 \%$. The highest arboreal indexes were observed in the Vila Nova Municipal School, $A D I$ of $0,737 \mathrm{~m}^{2}$; SAI of 21.161 and SGAI of $1,555 \mathrm{~m}^{2} /$ student. It can be concluded that in schools there is still a lack of trees to improve the landscape aspect and provide shade and a higher priority is still needed for native species of Brazilian flora.

Keywords: Trees. Environmental Perception. Shading.

\section{Referências}

ALVAREZ, I. A.; OLIVEIRA, U. R.; MATTOS, P. P.; BRAZ, E. M.; CANETTI, A. Arborização urbana no semiárido: espécies potenciais da Caatinga. Colombo: EMBRAPA FLORESTAS, 2012. (DOCUMENTO 243). Disponível em: $<$ http://ainfo.cnptia.embrapa.br/digital/bitstream/ite m/75650/1/Doc.-243-arborizacao-urbana.pdf>. Acesso em: 02 ago. 2016.

APG IV. An update of the angiosperm phylogeny group classification for the orders and families of flowering plants: APG IV. Botanical Journal of the Linnean Society, [S.I], v.181, p.1-20, 2016.

AURÉLIO JUNIOR, A. M. Levantamento da arborização urbana da região sul de Londrina e estudo de impacto ambiental. Londrina, PR: UNIPAC, 2008.

BONAMETTI, J. H. Arborização Urbana. Revista Terra e Cultura, Londrina, v. 19, p. 51-55, 2008. Disponível em: $<$ web.unifil.br/docs/revista_eletronica/terra_cultura /36/terra\%20e20\%36-6.pdf $>$. Acesso em:15 set. 2015.

CALLEJAS, I. J. A.; DURANTE, L. C.; NOGUEIRA, M. C. J. A.; NOGUEIRA, J. M. C. J. A. Diversidade e índices arbóreos em ambientes escolares. Revista Eletrônica em Gestão, Educação e Tecnologia Ambiental, Santa Maria, v. 18, n. 1, p. 454-466, 2014.

CARVALHO, P. E. R. Espécies arbóreas brasileiras. Brasília, DF: EMBRAPA Informação Tecnológica, 2008. 593 p., v.3.

DANTAS, I. C.; SOUZA, C. M. C. Arborização urbana na cidade de Campina Grande, PB: Inventário e suas espécies. Revista de Biologia e Ciências da Terra, João Pessoa-Paraíba, v. 4, n. 2, 2004.2 Disponível em:<http://www.redalyc.org/articulo.oa?id=500402 05>. Acesso em: 20 set. 2015.

FAGUNDES, J. F.; BANDEIRA, G. L.; SIQUEIRA, A. B.; NEIS, F. A.; KONFLANZ, T. L. Arborização e jardinagem na Escola Municipal de Ensino Fundamental Assis Brasil em Palmeira das Missões-RS. Revista Eletrônica em Gestão, Educação e Tecnologia Ambiental, Santa Maria, v. 19, n. 2, p. 1162-1173, 2015.
FEDRIZZI, B.; TOMASINI, S. L. V.; CARDOSO, L. $M$. A vegetação no pátio escolar: um estudo para a realidade de Porto Alegre-RS. In: CONGRESSO BRASILEIRO DE ARBORIZAÇÃO URBANA, 7., 2003, Belém, PA. Anais...., Belém: 2003a. v.1, p.1-4.

FEDRIZZI, B.; TOMASINI, S. L. V.; CARDOSO, L. M. A Vegetação no Pátio Escolar: Um Estudo para as Condições das Escolas Municipais de Porto Alegre - RS. In: ENECS - ENCONTRO NACIONAL SOBRE EDIFICAÇÕES E COMUNIDADES SUSTENTÁVEIS, 3., 2003, São Carlos. Anais .... São Carlos: 2003b. v.1, p.1-12.

GREY, G .W.; DANEKE, F. J. Urban Forestry. New York: Jonh Wiley, 1978.

IBGE. Instituto Brasileiro de Geografia e Estatística. (2010). Disponível em: <http://www.censo.2010.ibge.gov.br>. Acesso em: 15 abr.2016.

LANGOWSKI, E.; KLECHOWICZ, N. A. Manual prático de poda e arborização urbana. Cianorte: APROMAC, 2001

LIMA NETO, E. M.; SOUZA, R. M. Índices de densidade e sombreamento arbóreo em áreas verdes públicas de Aracaju, Sergipe. Revista da Sociedade Brasileira de Arborização Urbana, Piracicaba - SP, v. 4, n. 4, p. 47-62, 2009.

LORENZI, H. Árvores Brasileiras: manual de identificação e cultivo de plantas arbóreas do Brasil. 4.ed. Nova Odessa: Plantarum, 2002a. v.1.

LORENZI, H. Árvores Brasileiras: manual de identificação e cultivo de plantas arbóreas do Brasil. 2.ed. Nova Odessa: Plantarum, 2002b. v.2.

LORENZI, H. Árvores brasileiras: manual de identificação e cultivo de plantas arbóreas nativas do Brasil. 5.ed. Nova Odessa: Instituto Plantarum, 2008.

LORENZI, H. Árvores Exóticas no Brasil: madeiras, ornamentais e aromáticas. 1.ed. Nova Odessa: Plantarum, 2003.

SAMPAIO, A. C. F.; ANGELIS, B. L. D. Inventário e análise da arborização de vias públicas de Maringá - PR. Revista da Sociedade Brasileira de Arborização Urbana, Piracicaba - SP, v. 3, n. 1, p. 37-57, 2008. 


\section{REA - Revista de estudos ambientais (Online)} v.18, n. 2, p.6-15, jul./dez. 2016

SANTOS, A. F.; JOSÉ, A. C.; SOUSA, P. A. de. Fitossociologia e diversidades de espécies presentes na arborização das praças de Gurupi TO, Sociedade Brasileira de Arborização Urbana, Piracicaba - SP, v. 8, n. 4, p. 36-46, $2013 . \quad$ Disponível $<w w w . r e v s b a u . e s a l q . u s p . b r / a r t i g o s \_c i e n t i f i c o s$ lartigo 71.pdf.>. Acesso em 20 set. 2015.

SILVA, A. G.; PAIVA, H. N.; GONÇALVES, W. Avaliando a arborização urbana. Viçosa: Aprenda Fácil, 2004.

SIMÕES, L. O. C.; MAROTTA, H.; PIRES, B. B. M.; UMBELINO, L. F.; COSTA, A. J. S. T. Índices de Arborização em espaço urbano: um estudo de caso no bairro de Vila Isabel. In: ENAU, 9., 2001, Rio de Janeiro, RJ. Anais... Brasília: 2001.

SOCIEDADE BRASILEIRA DE ARBORIZAÇÃO URBANA - SBAU. Carta a Londrina e Ibiporã. Boletim Informativo, v. 3, n. 5, p. 1-3, 1996.

VÉRAS, M. L. M.; ALVES, L. S.; ARAÚJO, D. L.; MELO FILHO, J. S.; ANDRADE, R. Arborização com plantas frutíferas em uma escola de ensino fundamental. Revista Terceiro Incluído, Goiânia, v. 4, n. 1, p. 135-143, 2014.

ZILLER, S. R. Plantas exóticas invasoras: a ameaça da contaminação biológica. Ciência Hoje, Rio de Janeiro, v. 30 , n. 178 , p. 77-79, 2001. 